\title{
OS CONTOS EDUCATIVOS NA EDUCAÇÃO AMBIENTAL PARA PRESERVAÇÃO FLORESTAL E FAUNÍSTICO NA LOCALIDADE DE MUNHINGA-MOÇAMBIQUE
}

\author{
Munossiua Efremo Macorreia ${ }^{1}$
}

Resumo: Tendo em vista o crescente desflorestamento, aumentando o desaparecimento de certas espécies vegetais medicinais e animais vê-se a necessidade de produzir este estudo, com a finalidade de incutir nas comunidades locais uma nova consciência, comportamento e comprometimento, minimizando as conseqüências das atitudes anti-ambientais para o futuro. Assim, destaca o contributo dos contos educativos na Educação Ambiental na preservação da "floresta e fauna-bravia", na perspetiva de inseri-los aos curricula educacionais, visando mudar a atitude das gerações vindouras face ao futuro ambiental. Para isso, trabalhamos com as estruturas tradicionais locais, as comunidades gerais, sobretudo, professores, para melhor compreender o legado dos contos educativos tradicionais ligados ao ambiente, com o objetivo de apresentar uma proposta de atividade com os aprendizes da escola primária do primeiro grau de Chingundo, através da utilização de contos educativos, trazendo discussões às percepções, promovendo o debate sobre o que podemos fazer para amenizar a degradação dos recursos florestais com a sua fauna-bravia na região em estudo, focando na Educação Ambiental, na conservação, na redução das emissões provocadas por desmatamentos e queimadas descontroladas, sensibilizando as comunidades locais no plantio das plantas nos lugares que apresentam maior degradação. A metodologia usada fundamentou no enfoque da interdisciplinaridade, dotando uma abordagem qualitativa. Os resultados revelaram que os contos educativos na Educação Ambiental, são vistos como algo irrelevante, dada a fraca divulgação pelas camadas científicas. Com isso, considera-se necessário compreender novas maneiras de preservação da natureza, como estratégia de mudança comportamental, para proporcioná-los um futuro ambiental sustentável.

Palavras-chave: Contos Educativos; Educação Ambiental; Preservação Florestal e Faunístico.

\footnotetext{
1Universidade Save-Unisave-Moçambique. E-mail: efremomunossiua@yahoo.com.br
}

revista brasileira educação ambiental 
Abstract: in view of the growing deforestation without the replacement of plants, increasing the disappearance of certain medicinal plant species and animals, there is a need for a new awareness, behavior and commitment in face of this situation in order to minimize the consequences of these anti attitudes. environmental for the future. Thus, it highlights the contribution of educational tales in Environmental Education in the preservation of the "forest and wildlife". in the perspective of inserting them in the educational curricula, aiming to change the attitude of the coming generations towards the environmental future, therefore, we work with the traditional local structures, the general communities, above all, teachers, to better understand the legacy of the traditional educational tales connected to the environment, with the objective of presenting a proposal of activity with the apprentices of the primary school of the first grade of Chingundo, through the use of educational tales, bringing the perceptions discussion, promoting the debate about what we can do to alleviate the degradation of resources forests with their wildlife in the region under study, focusing on Environmental Education, conservation, reducing emissions caused by deforestation and uncontrolled fires, sensitizing local communities in the replacement of plants in the places that present the greatest degradation. The methodology used was based on the interdisciplinary approach, providing a qualitative approach. The results revealed that the educational tales in Environmental Education are seen as something irrelevant, given the poor dissemination by the scientific layers. Thus, it is considered necessary to understand new ways of preserving nature, as a behavioral change strategy, to provide them with a sustainable environmental future.

Keywords: Educational Tales; Environmental Education; Forest and Wildlife Preservation.

\section{Introdução}

Na localidade de Munhinga, existem diversas diversidades, sendo o mais destacado os Téwes, cujas formas de convivências de vida caraterizam as relações harmoniosas que estes apresentam com o meio ambiente (flora e fauna). Os Téwes habitam o Centro e o Norte do distrito de Sussundenga, e o seu núcleo central é Morribane.

Evidenciamos os contos educativos, como meio primordial de preservação do meio ambiente (flora e fauna), pois é dos contos educativos tradicionais que as populações da localidade de Munhinga carregam consigo conhecimentos culturais, sejam na cura com os medicamentos tradicionais que são as ervas da mata, compreendendo que não pode existir a vida na terra planetária semo respeito pelo meio ambiente.

Com o passar do tempo e com a revolução industrial as atitudes das sociedades Téwes passaram a ter maior preocupação cada vez mais na posse e na obtenção do lucro, realizando diversas atividades impactantes que 
ultrapassam a capacidade de suporte do meio ambiente: queimadas descontroladas para a prática da caça furtiva, abertura de campos agrícolas, exploração da madeira que posteriormente é vendida no Continente Asiático concretamente na China.

Nesta perspectiva, ao longo da minha frequência na Licenciatura, no Mestrado e Doutoramento, tive a oportunidade de destacar os contos educativos tradicionais aqueles que por muito tempo não são valorizados pelas comunidades científicas e pelas sociedades em gerais, pois se julga que a tradição corresponde a um saber popular que não é conhecido por todos, algo contraditório, pois o homem, independentemente do poder científico que ostenta, ele é também um ser sócio-cultural-étnico-religioso que precisa respeitar algumas leis da natureza e da sua comunidade.

É neste pressuposto que, o saber científico deve ser visto como um processo de ensino aprendizagem que possibilita a interdisciplinaridade e transdisciplinaridade, onde o professor não se prende a um único conteúdo de ensino e sim pode trabalhar tanto os contos educativos tradicionais como os conceitos específicos da ciência falando sobre o meio ambiente da fauna e flora, da geografia local do território.

Assim, a Educação Ambiental deve ser entendida como um campo emergente e que sustenta inúmeras discussões, onde as questões da conservação da flora com sua fauna-bravia se tornam questões centrais que sejam ensinadas transversalmente com os saberes culturais, mostrando a "importância de valorizar o uso da língua materna na transmissão dos conteúdos no ensino escolar. Pois, auxilia na articulação das mensagens como um todo e sobre a trajetória para a compreensão e construção dos conhecimentos científicos" (SILVIO GALLO, 2000.p.18).

Indo ao encontro das necessidades ambientais florestais e faunísticos de acordo com a temática em estudo, surge-nos o seguinte problema de investigação: até que ponto a utilização de contos educativos tradicionais na Educação Ambiental possam contribuir para conscientização ambiental, desenvolvendo proposta de atividade que possibilita construir novas maneiras de estilo de vida, mudanças de atitudes e valores no uso e apropriação dos recursos florestais e faunísticos?

Portanto, o presente trabalho tem como objetivo apresentar uma proposta de atividade com os aprendizes da escola primária do primeiro grau de Chingundo, através da utilização de contos educativos, trazendo discussões e as percepções, promovendo o debate sobre o que podemos fazer para amenizar a degradação dos recursos florestais com a sua fauna-bravia na região em estudo, focando na Educação Ambiental, na conservação, na redução das emissões provocadas por desmatamentos e queimadas descontroladas, sensibilizando as comunidades locais no plantio das plantas nos lugares que apresentam maior degradação. 
Nesta vertente, os contos educativos devem ser vistos como elementos essenciais para uma educação global, orientada para a resolução dos problemas, em favor do bem-estar da comunidade humana, mostrando aos aprendizes que os contos constituem um recurso com bastante potencial na promoção de valores ambientais, desde que devidamente explorados possibilitam a construção de um conjunto de ações comuns compromissadas com a degradação florestal, aquecimento global, o degelo das calotas polares, a reciclagem, o calor e o frio em demasiado, a falta de água, dentre outras.

\section{Contos educativos na preservação florestal e faunística}

Segundo "a tradição oral" com origem na transmissão dos mais antigos, contos educativos constituem formas tradicionais muito divulgadas em Moçambique particularmente na localidade de Munhinga.

São narrados em qualquer lugar, mediante as necessidades educacionais de cada circunstância e momento durante ao período da noite e em volta da fogueira "shiara". Pois, antigamente, eram locais e momentos mais frequentes de sua transmissão dos mais velhos para os mais novos, ensinando as crianças a aprender o valor da conservação do meio ambiente (flora e fauna-bravia), a perceber as diferenças sociais e sexuais, a obedecer as autoridades paternas, etc.

Deste modo, percebe-se que a história cultural duma determinada região desempenha um valor muito importante, pelo modo com que trazem significados e formas de educar, fazendo com que sejámos ensinados diversos temas do meio ambiente, incluindo aí a Educação Ambiental (COSTA; HESSEL; SOMMER, 2003, p. 36-61).

A partir deste cenário, entende-se que os contos educativos na Educação Ambiental podem mudar hábitos, transformar a situação do planeta terra e proporcionar uma melhor qualidade de vida para as pessoas. $E$ isso, só se fará com uma prática de Educação Ambiental, onde cada indivíduo sinta-se responsável em fazer algo para conter o avanço da degradação florestal e faunístico.

É neste pressuposto, que os contos educativos na Educação Ambiental ganham maior relevância na vida cotidiana quando funcionam como meio de expressão ou produção cultural, instituindo múltiplas representações que passam a marcar os sujeitos e as suas visões de mundo (WORTMANN, 2004. p. 147-161).

Assim, os contos educativos no contexto educacional procuram colocar as crianças desde cedo, a compreenderem que o presente e o futuro do meio ambiente dependem do equilíbrio entre homem e natureza e do uso racional dos recursos naturais. 
Portanto, o educador deve desenvolver práticas pedagógicas solidárias e articuladas com a emancipação humana, enfatizando a relação existente entre consciência, conhecimento e valores culturais (TRISTÃO, 2013, p. 847-860).

É nesta contextualização, que se realizou a Conferência Internacional sobre o Ambiente Humano, promovida pela ONU em Estocolmo, Suécia em 1972, onde fizeram parte 113 países. A partir desta Conferência, recomendouse a criação de um Programa Internacional de Educação Ambiental (PIEA), cujo desenvolvimento foi reconhecido como sendo de fundamental importância para o enfrentamento e combate à crise ambiental no mundo.

Neste evento, sabemos que a maioria dos problemas ambientais que afetam o mundo planetário tem suas raízes na miséria, que por sua vez é gerada por políticas e problemas econômicos concentradores de riqueza e responsáveis pelo desemprego e degradação ambiental.

Assim, através dos contos educativos na Educação Ambiental podemos perceber que "existem formas mais inteligentes de se lidar com o meio ambiente, produzindo uma prática pedagógica objetivada no indivíduo e na transformação da mudança do seu comportamento" (GUIMARÃES, 2004, p. 26-27).

Portanto, ao trazer este tema para a discussão entendemos que os contos educativos são manifestações normais dos seres humanos, dos fatos sociais, das culturas e das respostas dos indivíduos frente à Educação Ambiental. Os contos educativos poderão aparecer mais ou menos acentuados, e devemos acostumar-nos a viver com eles, conservando o meio ambiente a partir dos seus ensinamentos (SACRISTÁN, 2002, p. 15).

Desta forma, acreditamos que na localidade de Munhinga, existem várias formas de organização social, cultural e religiosa, na qual a escola primária do primeiro grau de Chingundo deveria ter o "compromisso ético e político de preservar e reafirmar valores, crenças e costumes, sem prejudicar o acesso e a apropriação dos saberes tradicional e conhecimentos universais" (MINED/ PCEB, 1999, p. 8).

Assim, a assimilação dos contos educativos na Educação Ambiental dentro da sala-de-aula é importante ter em conta a diversidade dos indivíduos e dos grupos sociais, para que se torne num fator, por excelência, de coesão social e não de exclusão.

"Na verdade, quando os contos educativos são abordados no contexto ambiental, existe um confronto perante as novas maneiras de convivência ambiental, mas esse conflito, bem gerido, deve ser encarado como uma oportunidade de" introduzir na escola as novas tecnologias de informação e comunicação e de se dialogar com os processos de mudanças culturais, presente em toda a população, tendo, no entanto maior incidência entre os jovens e as crianças, configurando suas identidades" (CANDAU, 2013, p.34). 
A partir deste pressuposto, existe a necessidade de pensar a Educação Ambiental como sendo uma prática educativa à luz da relação entre os saberes dos educadores com os saberes dos educandos, visto que pertence a grupos linguísticos étnicos e religiosos das comunidades "Téwes", com concepções e saberes diferenciados.

Para isso, é importante fazer o uso dos contos educativos no ensino escolar por meio do uso da língua materna, permitindo navegar em outras disciplinas/saberes que envolvem a ciência, meio ambiente, linguagem, histórias etc., que não são explicitados nas disciplinas escolares, avaliando a importância de se levar em consideração os saberes tradicionais (SILVIO GALLO, 2000.p.18).

Portanto, as comunidades locais, sobretudo os professores que lecionam na escola primária do EP1 de Chingundo não devem contentar-se em reconhecer os contos educativos e em valorizá-los, é necessário considerar e criar também os contos educativos nas práticas de ensino. Pois, a diversificação das práticas de ensino Moçambicano não é um empreendimento fácil. Ela é um dos maiores desafios do Ministério da Educação e Desenvolvimento Humano, tomando em conta a complexidade da sociedade moçambicana. São várias as questões que se colocam:

a). Devemos ter currículos diferentes para alunos com culturas locais diferentes?

b). O que significa realmente diversificar o currículo moçambicano? Ter conteúdos, objetivos, meios e estratégias de ensino diferentes?

Diante este cenário, o Sacristán (2002, p. 231-232), declara que:

ao reconhecer a importância dos contos culturais educativos e as diferenças entre os sujeitos existem duas opções curriculares fundamentais: a separação de sujeitos por culturas (currículo multicultural comunitarista); b). Educação comum (currículo comum pluralista) que pretende articular "certa interculturalidade a partir das ideias do pluralismo e da hibridação das culturas locais".

A ideia do autor acima, leva nos a pensar que ainda existem muitos desafios, pois os contos educativos na Educação Ambiental é um processo novo nos fundamentos educacionais Moçambicanos. Por isso, a discussão deste tema, exprime a intenção de agregar valores culturais, na medida em que propõem levar em conta elementos éticos na educação ecológicamente local. 


\section{Resultados e discussões}

A pesquisa a ser realizada fundamentou no enfoque da interdisciplinaridade, dotando uma abordagem qualitativa.

Para a coleta de dados foram utilizadas, técnicas de análise bibliográfica e trabalho de campo, recorrendo a entrevista semiestruturada, envolvendo as comunidades locais, estruturas tradicionais (régulos), aprendizes, sobretudo, professores, com objetivo de avaliar o trabalho que o professor realiza na área de Educação Ambiental, na perspectiva de ajudar os aprendizes a perceberem a importância dos contos educativos, na preservação dos recursos florestais e a sua fauna-bravia, construindo uma consciência global para que possam assumir como agente ativo no processo da abordagem das questões do meio ambiente no âmbito escolar.

De a cordo com Bogdan e Biklen (2000, p. 135), este tipo de entrevista é de caráter importante neste contexto de pesquisa, pois oferece ao pesquisador maior segurança e tem a vantagem de se ficar com certeza de obter dados comparáveis entre os vários sujeitos.

Assim, os dados coletados a partir da entrevista semiestruturada, foram interpretados através de conteúdos que, segundo Bardin (1977), tem por objetivo uma descrição analítica e sistemática, propiciando uma compreensão qualitativa do conteúdo das informações.

Os resultados da pesquisa, notamos que os aprendizes possuem pouca conscientização sobre os contos educativos na Educação Ambiental, porém não as relacionam com suas atividades diárias.

Do ponto de vista pedagógico, foi possível compreender que as práticas educativas e as propostas pedagógicas realizadas no interior da escola primária do primeiro grau de Chingundo, não trazem a conscientização pertinente, provocando indagações e permitindo olhar de outra forma para os professores, alunos e para a própria realidade da escola.

Assim, a partir dos resultados partilhados acima, segundo as informações coletadas junto a comunidade da localidade de Munhinga, enquanto militar das Forças Armadas de Defesa de Moçambique (FADM) e pesquisador, fomos narrado um conto tradicional mais popular na região em estudo. O conto é narrado a seguir:

\footnotetext{
"Há muito tempo numa aldeia, havia um homem que era muito caçador". Todos os dias, apanhava animais dzoma "gazela", tsuro "coelho", tsenzi "ratazana" e outros. Um dia encontrou-se com um leão e este Ihe perguntou:

-És tu aquele caçador que apanha sempre caça e está cabar animais aqui na floresta, ao ponto de nós "Madodas" "mais velhos da zona" não terem o que comer? O homem ficou todo trémulo com aquelas palavras. O leão prosseguiu e disse:
} 
- A partir de agora, por cada animal que apanhares na armadilha ou abater com a sua zagaia, deixa-nos uma parte e outra a leva consigo.

O homem concordou e passou a fazer como o leão lhe ordenara, mas a mulher passou a desconfiar e ficar aborrecida com aquele procedimento e pensou que o marido estava a ludibriar e que tinha outra mulher, sua rival, e ousou perguntar:

- Há muito tempo você trazia animal inteiro como é que agora traz metade? O homem tentou explicar a mulher, dizendo que na floresta os Adzimus "espíritos", Ihe exigiam que deixasse uma parte para os mais velhos "Madodas" da floresta.

Um dia a mulher quis certificar estas palavras e perseguiu o marido, mas numa moita da floresta foi apanhada por uma armadilha do marido e ficou suspensa de cabeça para baixo. O leão passou por aquelas bandas e quando viu a presa disse:

-O homem ainda não chegou; Vou comer a metade que sempre ele me dá e deixar-Ihe-ei a outra metade.

Quando o leão se preparava para tal eis que apareceu o homem e disse o leão ao homem:

-Eu já ia tomando conta da caça, mas só queria aquela metade que me prometeste, já que vi um animal na sua armadilha.

-O homem titubeando e surpreso por ver a mulher suspensa na armadilha disse:

-Não M'phandua "Excelência" esta não é carne, é minha mulher; perseguiu-me até cá na floresta para ver a quem eu dava a parte da carne que eu apanhava. Não acreditou que deixava a carne para Madoda "mais velhos da floresta" e pensou que eu tivesse outra mulher.

O leão fitou bem a mulher nos olhos com fúria e disse:

-Eu é que é tua rival. Agora vou te comer.

A mulher estremeceu, o marido implorou misericórdia e o leão sentenciou:

-Ao seu marido só exigia um pedaço da carne para juntos desfrutarmos o que os adzimus legaram, mas tu querias tudo para ti. Sabes tu que tenho poderes imensuráveis para caçar na floresta, mas obedeço aos antepassados no sentido de cuidar da floresta e de tudo o que nela existe.

- Hoje te perdoou, mas tenha em mente que o que Muari "Deus" e os antepassados fizeram, deve ser repartido por todos, deve ser usado sem egoísmo, deve criar harmonia.

Analisado atentamente este conto, demonstra que fica clara a preocupação de se ensinar às comunidades locais, principalmente para os aprendizes do ensino primário do primeiro grau de Chingundo, sobre o uso sustentável do meio ambiente (flora e fauna). Por outro, também educa a necessidade da partilha e a eliminação do egoísmo.

Revbea, São Paulo, V.16, № 5: 521-531, 2021. 
Na povoação de Munhinga, em entrevista com os professores que dão aulas na escola primária do primeiro grau de Chingundo explicaram que, os contos têm grande importância, muito principalmente na relação harmoniosa entre o homem e o meio ambiente (flora e fauna). Essa informação é secundada pelo Viola Mahama Mathuvera, de 86 anos de idade, membro do tribunal comunitário da localidade de Munhinga.

O mesmo relata um conto caraterístico das noites de shiara "fogueira", onde o conto é intercalado com canções e o relator repetindo e dramatizando, assume verdadeira figura de mestre, o conto é narrado a seguir:

"Havia numa aldeia uma mulher, que tinha um cão muito inteligente e que ajudava muito. Um dia foi ao bosque apanhar lenha e a dado passo se deparou com uma hiena e a mulher fugiu aterrorizada e subiu para cima de uma árvore. O dia declinava, a hiena estava em baixo da árvore, a mulher em desespero pôsse a cantar:

"Epfiepfi (vem) Matshena (nome do cão)

Imbwayangu Matshena (meu cão Matshena)

Ndofaherendi sina kukuona" (vou morrer sem te ver)

"Epfiepfi Matshena

Imbwayangu Matshena

Ndofaherendi sina kukuona"

"O cão ouviu a lamentação da sua dona e veio a salvá-la"

O significado deste conto demonstra profundamente e de uma forma indireta, a importância dos animais, tanto domésticos quanto selvagens. $E$ também mostra que, é na floresta onde conseguimos combustível lenhoso. Isto justifica a necessidade de se preservar o meio ambiente (flora e fauna).

O conto desempenha o papel crucial de despertar a noção imaginária popular de responsabilidade comum para com a natureza.

Temos como exemplo, mediante as informações coletadas junto às comunidades locais, enquanto militar e pesquisador constataram que, para preservar o património cultural de Moatize na Província de Tete, a Vale criou um projeto designado padawa-padawa "nome do projeto". Contos comunitários a volta da fogueira, visando a integração cultural entre diversas gerações, transmissão do saber tradicional e os valores culturais locais. Onde os mais velhos tem a oportunidade de dialogar com os mais novos transmitindo oralmente os valores culturais, cujo este ensinamento é maior de idade. Pois, os conhecimentos construídos serão guardado na memória e repassado posteriormente para as próximas gerações carente do saber tradicional (Figura 1): 


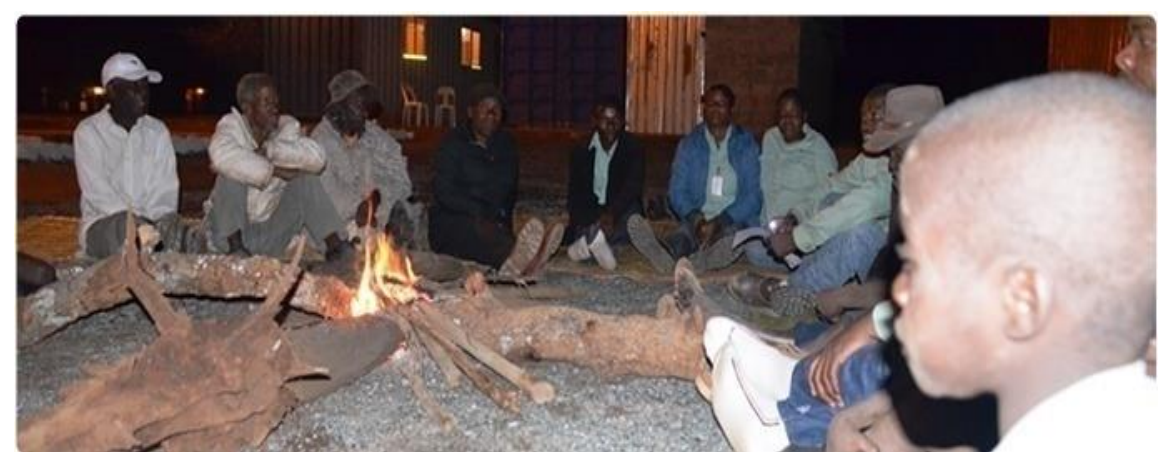

Figura 1: llustra conto comunitário a volta da fogueira "shiara".

Fonte:http://www.vale.com/PT/aboutvale/news/Publishinglmages/vale-resgata-contospreservacao-patrimonio-cultural.jpg

\section{Reflexões finais}

O trabalho feito com as comunidades locais, estruturas tradicionais, sobretudo, professores, chegou à conclusão que o ensino de contos educativos na Educação Ambiental na escola primária do EP1 de Chingundo na localidade de Munhinga, ainda existem muitas lacunas, para isso é fundamental a formação das crianças que serão os adultos de amanhã, criando as bases para a compreensão holística da realidade local e caminharmos para um planeta que, realmente possa ser sustentável.

Também, foi possível identificar que de facto o currículo do ensino primário do primeiro grau não contempla os contos educativos, dificultando a elaboração de projetos socioambientais que refletem a trajetória social em defesa à busca por um ambiente adequado para se viver.

Assim, sugerimos que o primeiro passo seja a formação dos professores, capazes de trabalhar com as formas tradicionais locais, introduzindo uma disciplina denominada "Didática de Contos Educativos na Educação Ambiental", nos cursos de formação dos professores primários do primeiro grau, cujo objetivo geral seria refletir sobre as relações existentes entre educação, conhecimento e cultura. Tal disciplina seria uma área científica que englobaria conhecimentos das áreas dos estudos de Antropologia Cultural, Pedagogia, Sociologia da Educação, Psicologia da Educação, Didática Geral, Psicolinguística, Sociolinguística e Teoria Curricular.

Portanto, os contos educativos, devem ser vistos como uma das formas tradicionais de Educação Ambiental, que faz parte de um processo de troca dos saberes, privilegiando a racionalização instrumental em detrimento dos conhecimentos, valores e atitudes voltadas a formação integral e humana dos sujeitos, nas suas relações entre si, e destes com a natureza.

Assim, preservar os contos educativos na localidade de Munhinga, é valorizar a identidade para o processo de transformação da sociedade atual em "uma sociedade que seja consciente e preocupada com o meio ambiente e com os problemas que Ihes são associados. Uma sociedade que tenha 
conhecimento, habilidade, atitudes, motivações e compromissos que the permita trabalhar individualmente e coletivamente na resolução dos problemas atuais e impedir que se repitam" (...) (SEARA FILHO,G. 1987, p. 65).

Contudo, sugerimos que os contos educativos sejam incorporados nos conteúdos curriculares de todos os níveis de ensino, desenvolvendo novos hábitos e atitudes sadias de conservação ambiental e respeito à natureza, a partir da consciencialização e Educação Ambiental pública que possibilita agir corretamente para a proteção do meio ambiente, mobilizando reuniões, debates e discussões de ações que possibilitam a sustentabilidade ambiental adequada e viável à vida das comunidades locais.

\section{Referências}

BARDIN, L. Análise de conteúdo. Lisboa: Edições 70, 1977

BOGDAN, R.; BIKLEN, S. Investigação qualitativa em educação: Uma introdução à teoria e aos métodos. Porto: Porto Editora, 2000.

CANDAU, V. M. Multiculturalismo e educação: desafios para a prática pedagógica. In: MOREIRA, A. F.; CANDAU, V. M. (Orgs.); Multiculturalismo: diferenças culturais e práticas pedagógicas. 10 ed. Petrópolis: Vozes, 2013

COSTA, M.V.; HESSEL, R.S.; SOMMER, L.H. Estudos culturais, educação e pedagogia. Revista Brasileira de Educação, Maio/Jun/Jul/Ago № 23/2003.

GALLO, S. Transversalidade e educação: pensando uma educação não disciplinar. O sentido da escola, v. 2, 2000.

MINED (Ministério da Educação). Plano curricular do Ensino Básico (PCEB). Maputo: MINED, 1999.

SACRISTÁN, J. G. Educar e conviver na cultura global: as exigências da cidadania. Porto Alegre: Artmed, 2002.

SEARA FILHO, G. Apontamentos de introdução à Educação Ambiental. Revista Ambiental, ano 1, v. 1. 1987

TRISTÃO, M. Uma abordagem filosófica da pesquisa em Educação Ambienta, v.18, n.55, Associação Nacional de Pós-Graduação e Pesquisa em Educação Rio de Janeiro, Brasil, 2013.

WORTMANN, M.L.C. Por que se valer do cinema, da mídia, da literatura, da televisão para discutir a natureza/ambiente? In: ZAKRZEVSKI, S.B.; BARCELOS, V. (Orgs.). EA e Compromisso Social: pensamentos e ações. Erechim, RS: Edifapes, 2004. 